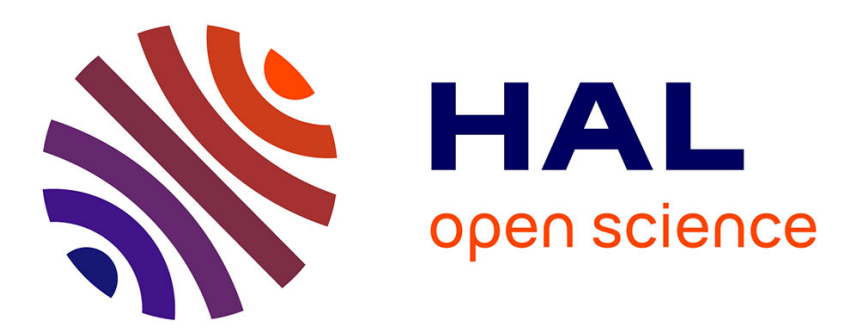

\title{
Structure, dynamics and phase separation of measles virus RNA replication machinery
}

Serafima Guseva, Sigrid Milles, Malene Ringkjøbing Jensen, Guy Schoehn, Rob W H Ruigrok, Martin Blackledge

\section{- To cite this version:}

Serafima Guseva, Sigrid Milles, Malene Ringkjøbing Jensen, Guy Schoehn, Rob W H Ruigrok, et al. Structure, dynamics and phase separation of measles virus RNA replication machinery. Current Opinion in Virology, 2020, 41, pp.59-67. 10.1016/j.coviro.2020.05.006 . hal-03016129

\section{HAL Id: hal-03016129 \\ https://hal.univ-grenoble-alpes.fr/hal-03016129}

Submitted on 23 Nov 2020

HAL is a multi-disciplinary open access archive for the deposit and dissemination of scientific research documents, whether they are published or not. The documents may come from teaching and research institutions in France or abroad, or from public or private research centers.
L'archive ouverte pluridisciplinaire HAL, est destinée au dépôt et à la diffusion de documents scientifiques de niveau recherche, publiés ou non, émanant des établissements d'enseignement et de recherche français ou étrangers, des laboratoires publics ou privés. 
Structure, dynamics and phase separation of measles virus RNA replication machinery

Serafima Guseva, Sigrid Milles, Malene Ringkjøbing Jensen,

Guy Schoehn, Rob W.H. Ruigrok, Martin Blackledge

Univ. Grenoble Alpes, CNRS, CEA, IBS, F-38000 Grenoble

Correspondence to:

rob.ruigrok@ibs.fr, martin.blackledge@ibs.fr

Declarations of interest: none 


\begin{abstract}
The measles virus replication complex represents a potentially important, but as yet relatively unexplored target for viral inhibition. Little is known about the molecular mechanisms that underpin replication and transcription in paramyxoviruses. In recent years it has become clear that conformational dynamics play an important role in paramyxoviral replication, and that a complete understanding of the viral cycle requires a description of the structural plasticity of the different components. Here we review recent progress in this direction, covering the dynamics of the nucleocapsid assembly process, high resolution structure and dynamics of protein:RNA interactions, and the investigation of the role of intrinsic conformational disorder in pre-assembly nucleoprotein/phosphoprotein complexes. Finally, we discuss the role of viral factories in the form of phase-separated membraneless organelles formed by measles virus phospho and nucleoproteins that promote the assembly of nucleocapsid structures.
\end{abstract}


Paramyxoviruses are non-segmented negative sense RNA viruses, including Measles (MeV), the most infectious human pathogen that still has a global mortality of 140,000 per year, as well as numerous emerging human pathogens with extremely high mortality rates. There are currently no effective treatments to combat $\mathrm{MeV}$ infection, whose impact is increasing throughout the world due to incomplete vaccine coverage [1]. The replication complex represents a promising, but relatively unexplored therapeutic target. Paramyxoviral replication machinery comprises the nucleoprotein $(\mathrm{N})$, whose major role involves encapsidation of the viral genome, the RNA-dependent RNA polymerase $(L)$ and its cofactor the phosphoprotein (P) [2-4].

Each $\mathrm{MeV} \mathrm{N}$ protein binds to six nucleotides of the viral genome or antigenome during encapsidation, assembling into helical nucleocapsids that are thought to protect the viral RNA from recognition and degradation by the innate immune system. $\mathrm{N}$ is chaperoned in the unassembled form by $\mathrm{P}$ prior to encapsidation, in the so-called $\mathrm{N}^{0} \mathrm{P}$ complex, and is thought to co-localize $\mathrm{N}$ and $\mathrm{L}$ during the replication process $[5,6]$.

$\mathrm{N}$ and $\mathrm{P}$ both present a significant amount of conformational plasticity, comprising structured domains as well as highly disordered domains. Approximately 30 and $75 \%$ of the primary sequences of $\mathrm{N}$ and $\mathrm{P}$ lack tertiary structure respectively (figure 1 ), and fall into the category of intrinsically disordered proteins. $\mathrm{N}$ consists of a folded domain ( $\left.\mathrm{N}_{\mathrm{CORE}}\right)$, that binds the viral RNA in the nucleocapsid structure, preceded by disordered 34 and 17 amino acid (aa) N- and C-terminal arms ( $\mathrm{N}_{\text {ARM }}$ and $\mathrm{C}_{\text {ARM }}$ ), and followed by a 134 aa flexible domain ( $\mathrm{N}_{\text {TAIL }}$ ) [7] that remains dynamic in the context of assembled nucleocapsids [8]. The presence of $N_{\text {TAlL }}$ appears to introduce a level of global flexibility in the nucleocapsid, resulting in an increased average distance between successive helical turns when the disordered domain is present $[9,10]$. Flanking regions of $\mathrm{N}_{\text {CORE }}, \mathrm{N}_{\text {ARM }}, \mathrm{C}_{\mathrm{ARM}}$ and the $\mathrm{N}$-terminal end of $\mathrm{N}_{\text {TAlL }}$, stabilize the helical superstructure of nucleocapsids by binding to neighbouring $\mathrm{N}$ molecules upon interaction with RNA (figure 1). Deletion of the flanking regions of $\mathrm{N}_{\text {CORE }}$ also prevents assembly into nucleocapsid like particles (NCLPs). 
The polymerase cofactor $\mathrm{P}$ is tetrameric, consisting of a central coiled-coil domain [3], whose structural properties have recently been linked to $\mathrm{MeV}$ gene expression [11], flanked by a long (304 aa) intrinsically disordered N-terminal domain ( $\left.\mathrm{P}_{\text {TALL }}\right)$ [12] and a shorter (80 aa) disordered domain ( $P_{\text {LOOP }}$ ) that is terminated by a small C-terminal three-helix bundle $(X D)$ [13] which interacts with a short helical linear motif in $\mathrm{N}_{\text {TAlL }}[7,13,14]$. This level of disorder is replicated, in morbilliviruses and other paramyxoviruses ( $\mathrm{P}_{\text {TAlL }}$ in Nipah virus is 470 aa long). The $\mathrm{N}$ terminal 30 amino acids of MeV $\mathrm{P}_{\text {TAlL }}$ are known to interact tightly with $\mathrm{N}$, via a helix-kink-helix conformation [15], forming a heterodimeric chaperone $\left(\mathrm{N}^{0} \mathrm{P}\right)$ that inhibits assembly of $\mathrm{N}$ into nucleocapsids (figure 1). The sites on $\mathrm{N}_{\mathrm{CORE}}$ that interact with the neighbouring flanking arms in nucleocapsid structures coincide with the binding sites of the two helices of $\mathrm{P}_{\text {TAlL }}$ in the $\mathrm{N}^{0} \mathrm{P}$ complex, suggesting an inhibitory mechanism that maintains $\mathrm{N}$ in the unassembled state.

The functional role of the remainder of this extensive disorder has remained unclear. The conserved presence of such long disordered domains in viruses is all the more remarkable considering the parsimonious nature of their genetic material. Intrinsic disorder in paramyxoviral proteins has been rendered yet more intriguing by the recent observation that disordered domains play important roles in the formation of membraneless organelles that appear to act as viral replication factories [16-18].

The combination of structured and highly flexible domains in functional complexes requires the application of multi-disciplinary approaches that are capable of capturing the atomic detail of both the structure and dynamics of these highly plastic assemblies [19]. Here we summarize recent structural, dynamic and functional descriptions of these highly dynamic assemblies using a combination of solution and solid-state structural biology.

\section{In vitro reconstitution of the $\mathrm{MeV}$ nucleocapsid assembly process}

One major reason for the relative lack of understanding of the RNA genome (and anti-genome) encapsidation process stemmed from the difficulty in isolating $\mathrm{N}$, prior to assembly, due mainly to the high propensity of $\mathrm{N}$ to bind cellular RNA (for example when expressed in $E$. coli or insect cells) and spontaneously assemble into NCLPs. Experimentally this has allowed the 
purification of MeV NCLPs and the determination of increasingly high-resolution structures of

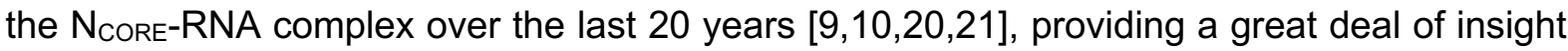
into the mechanisms of stabilization described above, but the kinetic process of assembly remained poorly characterized. Inspired by the mechanism exploited by the virus itself to stabilize $\mathrm{N}^{0} \mathrm{P}, \mathrm{N}$ and $\mathrm{P}$ were co-expressed as a fusion construct, separated by a TEV cleavage site, which allowed the purification of $\mathrm{N}^{0} \mathrm{P}$, where $\mathrm{P}$ can be of any length as long as the $\mathrm{N}$ terminal binding site is included in the construct. This tool provides access to conformational characterisation of $\mathrm{N}^{0} \mathrm{P}$ complexes comprising different levels of disorder (figure 1), direct investigation of NCLP assembly [22] and control of the RNA present in the complex.

Indeed, addition of short RNA molecules was shown to trigger formation of NCLPs (figure 1D). The process can be observed in real time using NMR - by observing the appearance of ${ }^{15} \mathrm{~N}$ ${ }^{1} \mathrm{H}$ cross-peaks from amino acids in the P-peptide that detach from N $\mathrm{N}_{\text {CORE }}$ upon NCLP formation, and the disappearance of flexible peaks from $\mathrm{N}_{\mathrm{ARM}}$ that become structured upon binding neighbouring $\mathrm{N}_{\mathrm{CORE}}$ domains. The process can also be observed using negative staining electron microscopy (EM) and more importantly fluorescence anisotropy, with fluorescein-labelled RNA. This latter revealed the presence of two steps in the assembly kinetics, one significantly faster than the other. The physical origin of the biphasic assembly is not yet known, for example whether the two steps correspond to binding of RNA and then inter-protomer assembly, or vice versa. Importantly a clear dependence on RNA sequence was observed, with polyA and the 5' end of the genome assembling with high efficiency, while some sequences, for example polyU did not assemble. This specificity suggests a role for nucleation of assembly via specific sequences ( 5 ' sequences of genome and anti-genomes are highly conserved in Paramyxoviridae).

\section{Cryo-EM structure of RNA-specific MeV nucleocapsids reveals new mechanistic insight}

While interactions between N and RNA in MeV NCLPs have been investigated for using EM and cryo-EM $[9,20,10,21]$ and in single turns crystallised as closed rings in a number of related viruses [23-26], in all cases the particles were purified in the assembled form after 
overexpression in cellular systems. The particles therefore contained random cellular RNA at each position, so that only sequence-averaged structural information is obtained, precluding the determination of protein-base interactions. Nevertheless, the binding mode of the RNA to $\mathrm{MeV} \mathrm{N}$ was shown to comprise three bases pointing into, and three bases pointing away from the RNA binding groove $[21,26]$. In order to gain further insight, NCLPs were polymerized on polyA and viral genomic 5' (ACCAGA) sequences using the approach described above, and their three-dimensional structures determined using cryo-EM to $3.4 \AA$ resolution [27].

The 5' and 3' binding sites were unambiguously identified (figure 2), and thereby the register of binding of viral genomic RNA within the assembled NCLPs. This implies that the final three nucleotides at the 3' end of the genome are almost fully exposed in assembled nucleocapsids (figure 2), allowing access to the genome for the RNA-dependent RNA polymerase complex [28]. Putative protein-nucleobase interactions were identified in the RNA-binding groove (figure 2). In particular the sidechain of R195 was found to stabilize nucleic acid backbone and base via a tight bipartite interaction (figure 2). This interaction was then shown to be essential for assembly using mutagenesis, negative staining EM and real-time NMR [27].

\section{$\mathrm{N}^{0} \mathrm{P}-\mathrm{A}$ complex story of disorder and allostery}

The role of $\mathrm{P}_{\mathrm{TAlL}}$ domain was recently investigated by co-expressing integral $\mathrm{N}$ with $\mathrm{P}_{\text {TAIL }}$ (1304), thereby stabilising the $90 \mathrm{kDa} \mathrm{N}^{0} \mathrm{P}_{\text {TAlL }}$ sub-complex, comprising the disordered regions $P_{\text {TAlL, }} \mathrm{N}_{\text {ARM }}$ and $\mathrm{N}_{\text {TAll }}$ (in total over 450 disordered amino acids) as well as $\mathrm{N}_{\text {CORE. }} \mathrm{NMR}$ spectroscopy allows the atomic resolution description of each disordered region in such highly dynamic complex (figures 1,3$)[19,29,30]$. This study [12] revealed that, in addition to the known binding site at its $\mathrm{N}$-terminus, $\mathrm{P}_{\text {TAIL }}$ contains an additional helical linear motif, ${ }^{191} \mathrm{HELL}{ }^{194}$ ( $\alpha 4$ ), that binds weakly (with an intrinsic $K_{D} \sim 600 \mu M$ ) to the surface of the $\mathrm{N}$-terminal lobe of $N_{\text {CORE. }}$ This secondary binding site is the most evolutionarily variable part of $N_{\text {CORE }}$ [31] and has been shown to be implicated in binding of cofactors of VSV [32] and RSV [33] and was exploited via chimeric constructs to be implicated in $\mathrm{N}_{\text {TAIL }}: \mathrm{XD}$ interactions localised on the surface of $\mathrm{N}_{\text {CORE }}[34]$. 
Remarkably, mutation of this site to ${ }^{191} \mathrm{AAAA}^{194}$ in cell-based MeV mini-genome studies revealed that the HELL site is essential for viral transcription and replication. Equivalent motifs comprising two bulky hydrophobic residues at the C-terminus of a short helical motif are conserved across morbilliviruses and paramyxoviruses comprising $\mathrm{P}_{\text {TAlL }}$ domains of very different length, such as Nipah (470 amino acids comprising $\left.{ }^{343} \mathrm{RELL}^{346}\right)$. These sequences show significantly higher sequence conservation over non-redundant $\mathrm{MeV}$ sequences than the majority of $\mathrm{P}_{\text {TAlL}}$, suggesting that this motif may provide an important new target for treating paramyxoviruses, in particular in view of the relatively weak intrinsic affinity that renders this target accessible to peptide-based inhibitors.

This study therefore revealed a more complex picture of the $\mathrm{N}^{0} \mathrm{P}$ complex than previously envisaged - that comprises not one but (at least) two N:P binding sites, both of which are essential for viral function - and sheds new light on the conserved presence of long intrinsically disordered paramyxoviral $\mathrm{P}_{\text {TAlL }}$ domains [35]. When both sites are bound, the unfolded $\mathrm{P}_{\text {TAIL }}$ wraps around $\mathrm{N}_{\text {CORE, }}$, but because the affinity of the two binding sites differs by around 5 orders of magnitude, the HELL motif transiently binds and unbinds while the $\mathrm{N}$-terminal site is bound (figure 3). The impact of the highly dynamic 150 aa separating the two sites, comprising a cluster of acidic amino acids, may enhance chaperone function by frustrating interaction of RNA with the surface of $\mathrm{N}_{\text {CORE, }}$, impacting self-assembly with other $\mathrm{N}$ monomers or possibly regulating interactions with host factors involved in the immune response [36]. It should be mentioned that the construct investigated here comprises the genome-edited viral protein $\mathrm{V}$ [37-40] which is equivalent to $P_{\text {TAlL }}$ until residue 232 followed by a zinc finger domain. The observations made here are thus possibly equally valid for putative $\mathrm{N}^{0} \mathrm{~V}$ complexes. Finally the essential role of the HELL motif in MeV replication exemplifies the growing number of examples of ultra-weak interactions involving intrinsically disordered proteins in biology [41].

\section{$\mathbf{N}$ and $\mathbf{P}$ proteins form membraneless organelles that promote nucleocapsid formation}

As illustrated above, $\mathrm{N}$ and $\mathrm{P}$ proteins exhibit multiple essential interactions during the viral cycle, a multivalency that, in combination with their extensive intrinsic disorder and the 
transient nature of some of the associated interactions, may play a role in the formation of viral factories in infected cells [42,43]. Liquid-liquid phase separation (LLPS), by which microenvironments remain immiscible with respect to their immediate surroundings thereby maintaining distinct reaction or storage conditions within the condensate, are now thought to be prevalent throughout cell biology [44-46]. Intrinsic disorder plays a key role in the thermodynamic stabilisation of LLPS, due to the prevalence of weak and transient interactions that contribute to maintaining the liquid nature of the environment, and allowing rapid spatial and temporal control of biochemical processes [47].

The formation of membraneless organelles, in addition to concentrating viral partners in a confined volume, may also provide protection from factors involved in the host-immune response. Numerous examples of colocalization of Mononegaviral $\mathrm{N}$ and $\mathrm{P}$ have been observed in vivo, including rabies [48], VSV [49], human parainfluenza types 5 [40] and 3 [50,51], RSV [17], Nipah [52], human metapneumovirus [53], MeV [18,54-56] and Ebola [57]. A detailed study by Gaudin et al demonstrated the liquid-like nature of Negri bodies formed in rabies [16] and colocalization of $\mathrm{N}$ and $\mathrm{P}$ in infection-induced cytoplasmic inclusion bodies in $\mathrm{MeV}$ [18] suggests that LLPS represents a widespread mechanism exploited by Mononegaviruses during infection. These studies also investigate the role of transport of membraneless organelles along the cytoskeleton in the infection cycle $[16,18]$.

The formation of membraneless organelles comprising $\mathrm{MeV} \mathrm{N}$ and $\mathrm{P}$ proteins was recreated in vitro using co-expressed soluble $\mathrm{N}^{0} \mathrm{P}$ complexes and different constructs of $\mathrm{P}$ under conditions where neither $\mathrm{N}^{0} \mathrm{P}$ nor $\mathrm{P}$ undergoes phase separation (figure 4). Expression of combinations of the different domains (figure 1) identified the tetramerization domain of $P$, the disordered domain PLOOP and the three-helix bundle XD as essential for droplet formation ( $\mathrm{P}_{\text {TAIL }}$ is dispensable for LLPS). Integral $\mathrm{N}$, comprising the disordered $\mathrm{N}_{\text {TAlL }}$, is essential. These results align with those measured in $\mathrm{MeV}$ [18] and rabies [16] in vivo in terms of the essential domains required for LLPS. 
NMR spectroscopy was used to characterise the essential interactions, identifying the $N_{\text {TAlL }}: P_{X D}$ interaction [14,58-60] whose inhibition via a single mutation [61], results in abrogation of LLPS. A recent study also showed that XD deletion abolishes LLPS in vivo [18]. PLoop and $\mathrm{N}$ are also shown to interact via weak interactions $(200-400 \mu \mathrm{M})$ that affect droplet fluidity, suggesting that the role of $P_{\text {LOOP }}$ is not uniquely as a "spacer" [62] that ensures the physical separation of interacting components, but is also involved in regulating the dynamics of the droplets.

Investigation of the thermodynamics of droplet formation using NMR spectroscopy and the diffusion properties of the components using fluorescence imaging, revealed a probable mechanism of droplet stabilisation by which the tetrameric $\mathrm{P}$ protein interacts with $\mathrm{N}$ to form droplets, to which additional $\mathrm{N}$ proteins can be recruited, allowing for variable stoichiometry within the droplets [63]. P would then form a dynamic, multivalent scaffold comprising four branched dynamic XD interaction sites. Both $\mathrm{N}$ and $\mathrm{P}$ are highly dynamic within the droplets, but $\mathrm{P}$ diffuses slightly slower, in agreement with this model. As $\mathrm{N}$ is the most expressed $\mathrm{MeV}$ protein [64] and is required for assembly of nascent genomic material into nucleocapsids, such plasticity could be essential to allow for large variations of $\mathrm{N}$ concentration and fluid recruitment of $\mathrm{N}$ to droplets as nucleocapsids are produced.

Finally, and possibly most remarkably, membraneless organelles were shown to exhibit functional properties in vitro. Addition of RNA to a suspension of $\mathrm{N}: \mathrm{P}$ droplets revealed preferential localisation to the droplets, and triggering of nucleocapsid assembly. The rate of assembly, as measured by real-time NMR, was significantly increased compared to the dilute phase, and EM revealed NCLP-like structures within one hour of addition of RNA. These results demonstrate that the condensed environment does not restrict the assembly of large superstructures and that droplet formation indeed enhances one of the essential processes of viral replication. The mechanisms observed here may be of general interest in characterising and inhibiting mononegaviral infection. The role of $\mathrm{L}$, which is known to colocalize with $\mathrm{N}$ and $\mathrm{P}$ in mononegaviral puncta [49] remains to be characterised within viral coacervates. We note 
that the presence of messenger RNA has been detected in puncta associated with rabies [48], RSV [17] and PIV3 [51], implying that both transcription and replication may be associated with LLPS in negative sense RNA viruses.

In conclusion we have described recent work centred on the biophysical characterisation of MeV N:P interactions involved in essential processes of mononegaviral infection. These aspects range from the observation of nucleocapsid assembly, to the identification of key $\mathrm{N}:$ RNA interactions and template architecture, to the development of a new understanding of the role of intrinsic disorder in paramyxoviruses and finally the formation of viral factories by this machinery, providing a functional microenvironment within which the preceding biophysical features should also be understood. In combination with the rapid increase in structural information concerning paramyxoviral and related RNA-dependent RNA polymerase structures and their interactions with phosphoproteins [65-69], our physical understanding of the molecular basis of viral replication is currently making major advances that will undoubtedly lead to the development of rational inhibitory strategies. We look forward to future structural studies of integral replication machinery comprising the N/NCLPs, P and the polymerase.

Acknowledgements. The authors acknowledge integration into the Interdisciplinary Research Institute of Grenoble (IRIG, CEA). This work was supported by the European Research Council Advanced Grant DynamicAssemblies to MB, GRAL (ANR-10-LABX-49-01), Finovi, and FRM (Equipe DEQ20170336754). The work used the platforms of the Grenoble Instruct-ERIC centre (ISBG; UMS 3518 CNRS-CEA-UJA-EMBL) with support from FRISBI (ANR-10-INSB-05-02) and GRAL (ANR-10-LABX-49-01) within the Grenoble Partnership for Structural Biology (PSB). 


\section{Figure Legends}

Figure 1. Architecture of $\mathrm{MeV} \mathrm{N}$ and $\mathrm{P}$ proteins

A. N and P both contain long, disordered strands (orange) that flank and are interspersed between structured domains ( $\mathrm{N}_{\mathrm{CORE}}, \mathrm{PMD}$, the multimerization domain of $\mathrm{P}$ and $\mathrm{XD}$ ). The $\mathrm{N}$-terminal peptide of $\mathrm{P}_{\text {TAlL }}$ binds $\mathrm{N}_{\text {CORE }}$ in the $\mathrm{N}^{0} \mathrm{P}$ complex.

B. Cryo-EM structure of nucleocapsid reveals that $\mathrm{N}_{\text {ARM }}$ stabilizes nucleocapsid assembly by binding neighbouring protomers (similarly the C-terminal flanking $\mathrm{C}_{\mathrm{ARM}}$ 374-391). The $\mathrm{N}$-terminal peptide of $\mathrm{P}_{\text {TAlL }}$ adopts a pose that inhibits these interactions thereby maintaining $\mathrm{N}$ in an unassembled state as determined in reference [15] and [31] in the case of Nipah virus.

C. Co-expression of $\mathrm{P}_{\mathrm{TAlL}}$ (either 1-50 or 1-304) with $\mathrm{N}_{\text {CORE }}$ or $\mathrm{N}_{\mathrm{FULL}}$ chaperones $\mathrm{N}$ in a monomeric form $\left(\mathrm{N}^{0} \mathrm{P}\right)$ and allows for studies of the pre-assembly complex. The nucleocapsid assembly process is triggered by addition of RNA .

D. NMR and fluorescence spectroscopy and EM can be used to follow nucleocapsid assembly in real time as shown in references [22] and [27]. Following changes in peak intensity of NMR spectra of the complex it is possible to follow how the $\mathrm{P}$ peptide detaches from $\mathrm{N}_{\text {CORE }}$ and how $\mathrm{N}_{\mathrm{ARM}}$ and $\mathrm{C}_{\text {ARM }}$ bind (left figure). The assembly process can be investigated by observing fluorescently labelled RNA, which, when bound to $\mathrm{N}$ exhibits higher anisotropy (central figure). Nucleocapsids can be imaged using electron microscopy (right figure).

Figure 2. High resolution structure of RNA-specific MeV nucleocapsid-like particles (as determined in the recent publication [27]).

A. Helical reconstruction of nucleocapsid-like particles assembled in vitro on known RNA sequences determines the binding register of the RNA in the binding cleft, revealing that the last three 3' nucleotides in the genome are exposed. Three copies of $\mathrm{N}$ are shown, the central is shown in yellow cartoon format, with neighbouring copies shown 
in blue. The RNA (orange) is shown in the binding cleft, with 5 phosphate groups associated with the hexameric RNA molecule shown as spheres.

B. Detail of the protein-RNA interactions identified in the binding cleft due to the higher resolution structure and the unambiguous assignment of the electron density to the RNA sequence. The key interacting amino acids are shown in red. (reproduced from Desfosses et al PNAS 2019, 116:4256-4264).

C. R195 in particular is shown to adopt a bipartite interaction with the adenine in position 5. When this site is mutated no assembly is observed by NMR, fluorescence or EM. (reproduced from Desfosses et al PNAS 2019, 116:4256-4264).

Figure 3. The role of intrinsic disorder in the $\mathrm{MeV} \mathrm{N}^{0} \mathrm{P}$ complex (as determined from the recent NMR study of this $90 \mathrm{kDa}$ assembly [12])

A. Structural characterisation of MeV $\mathrm{P}_{\mathrm{TAIL}}$ at amino acid specific resolution. Four helical elements are found along the sequence ( $\alpha 1$ and $\alpha 2$ that correspond to the $\mathrm{N}$-terminal peptide that binds $\mathrm{N}_{\text {CORE, }} \alpha 3$ and $\alpha 4$ ). Reproduced with permission from Milles et al Science Advances 2018, 4:eaat7778.

B. Heteronuclear single quantum coherence (HSQC) spectrum of the $\mathrm{N}_{1-525}{ }^{0} \mathrm{P}_{1-304}$ complex comprising the entire $\mathrm{P}_{\mathrm{TAIL}}$ and integral $\mathrm{N}$. Reproduced with permission from Milles et al Science Advances 2018, 4:eaat7778.

C. HSQC peaks intensities provide insight into nature of the interactions between $\mathrm{P}_{\text {TAlL }}$ and $\mathrm{N}$. Top - In addition to the $\mathrm{N}$-terminal binding peptide, $\mathrm{P}_{\text {TAlL }}$ binds $\mathrm{N}$ via a second interaction site that corresponds to helix $\alpha 4$ (comprising the sequence HELL). Bottom - mutation of HELL to AAAA abrogates the second interaction site, and renders the virus incompetent for replication. Reproduced with permission from Milles et al Science Advances 2018, 4:eaat7778.

D. The intrinsic affinity of the HELL interaction site for $\mathrm{N}$ is approximately 5 orders of magnitude weaker than the $\mathrm{N}$-terminal site, such that the binding site exchanges 
rapidly between bound and unbound conformations. Reproduced with permission from Milles et al Science Advances 2018, 4:eaat7778.

E. An ensemble of conformations sampled by the $\mathrm{P}_{\text {TAIL }}-\mathrm{N}_{\text {CORE }}$ complex. This highly dynamic process may contribute to protection against non-specific binding of host RNA or factors involving the host immune system. Reproduced with permission from Milles et al Science Advances 2018, 4:eaat7778.

Figure 4. MeV N and $\mathrm{P}$ proteins form membraneless organelles that colocalize RNA and promote assembly of NCLPs.

A. PMD, PLoop and XD and integral $N$ constitute the minimal elements that can form droplets. Upon mixing with $\mathrm{N}, \mathrm{P}$ appears to act as a dynamic scaffold, to which additional $\mathrm{N}$ proteins can be recruited.

B. RNA colocalizes to N:P droplets (10 nucleotide polyA RNA is labelled with fluorescein in the example shown) and forms nucleocapsid like particles - a process that can be observed by NMR and EM. Reproduced with permission from Guseva et al Science Advances 2020, 6:eaaz7095. 

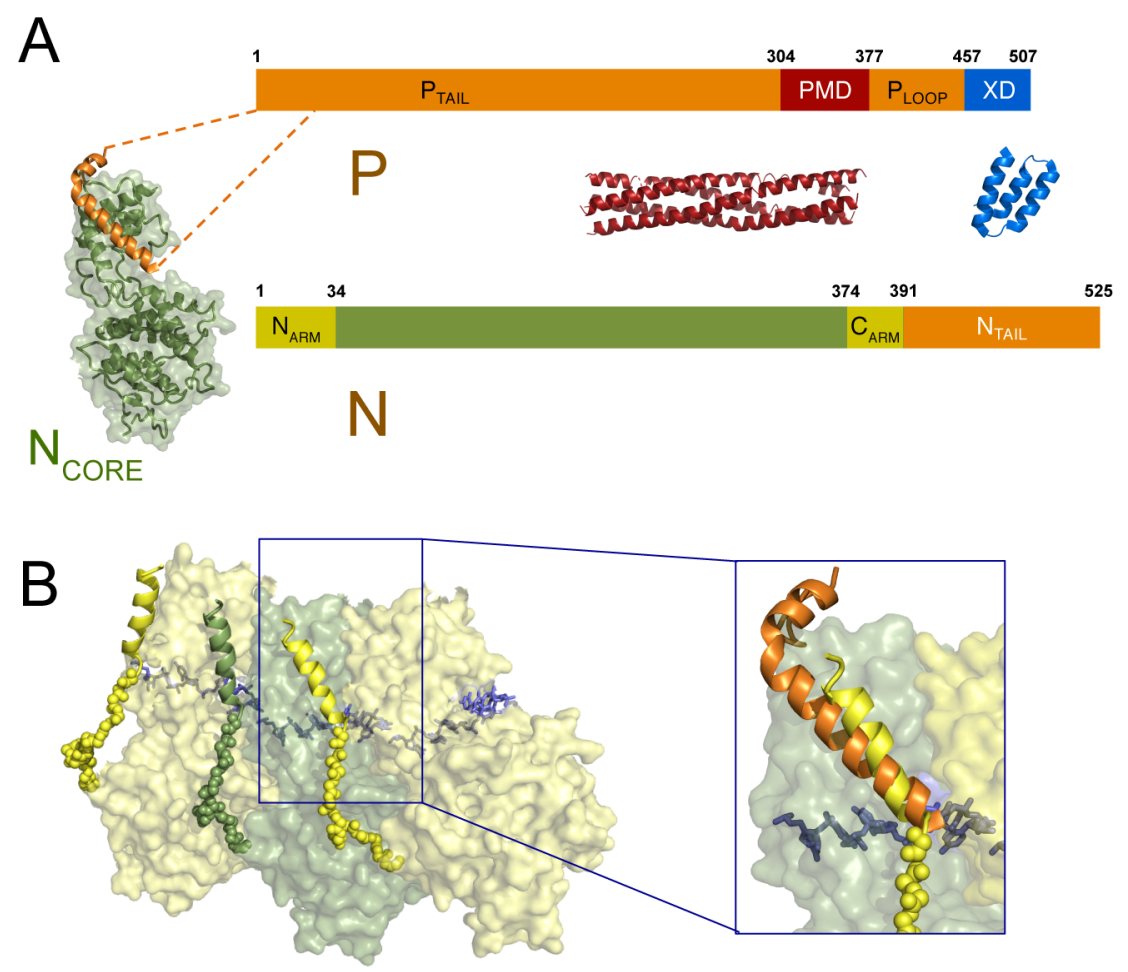

C
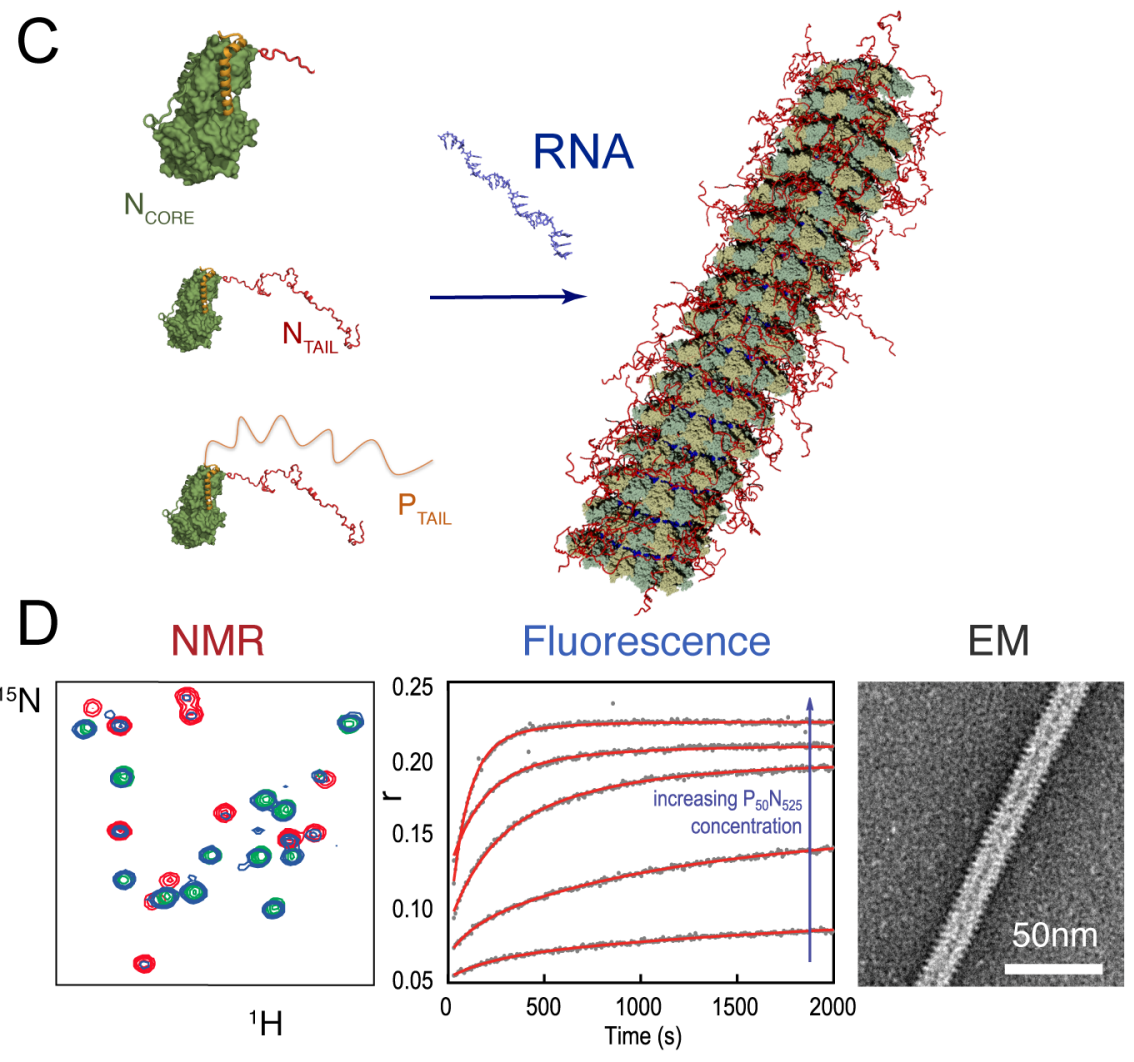


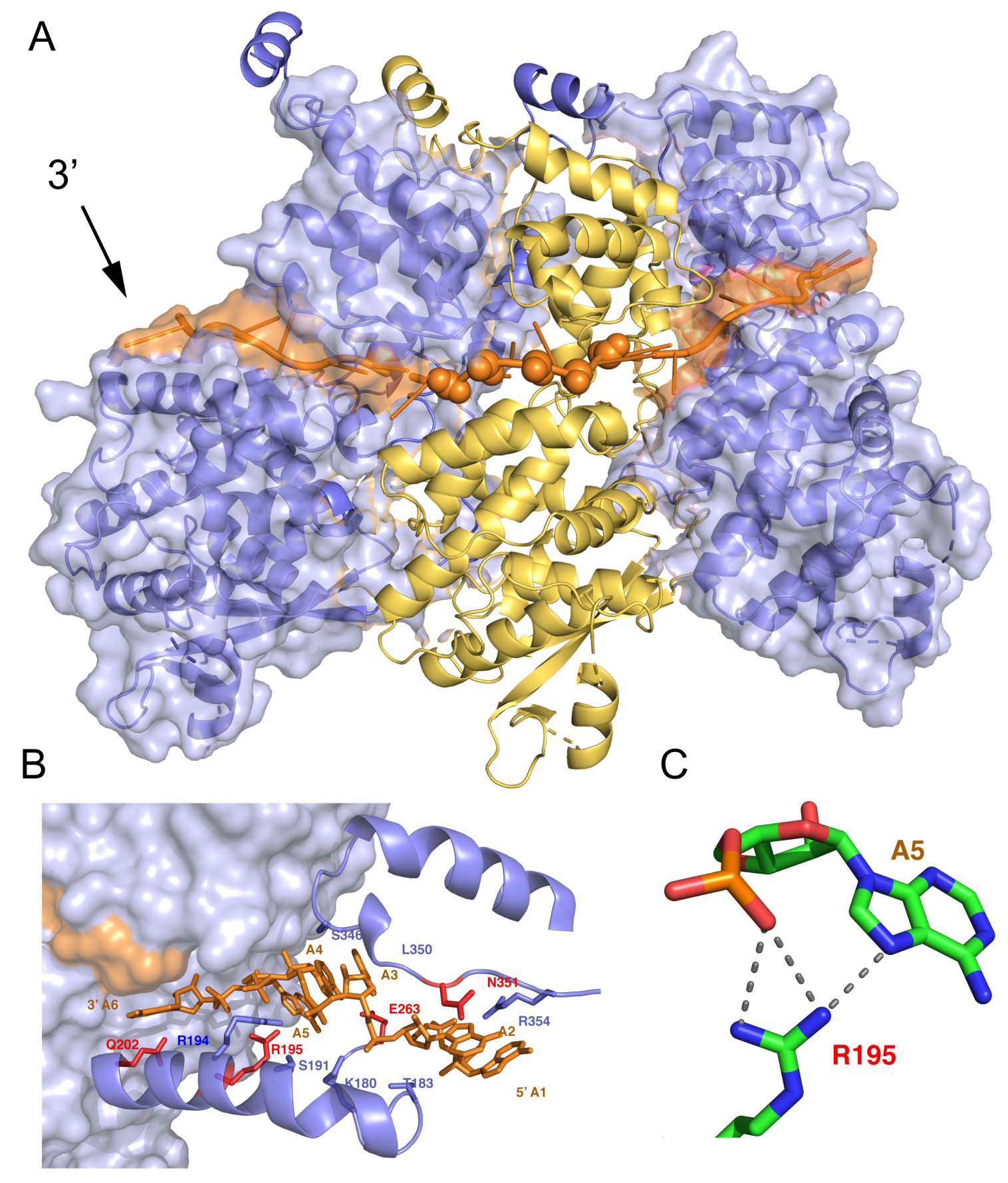



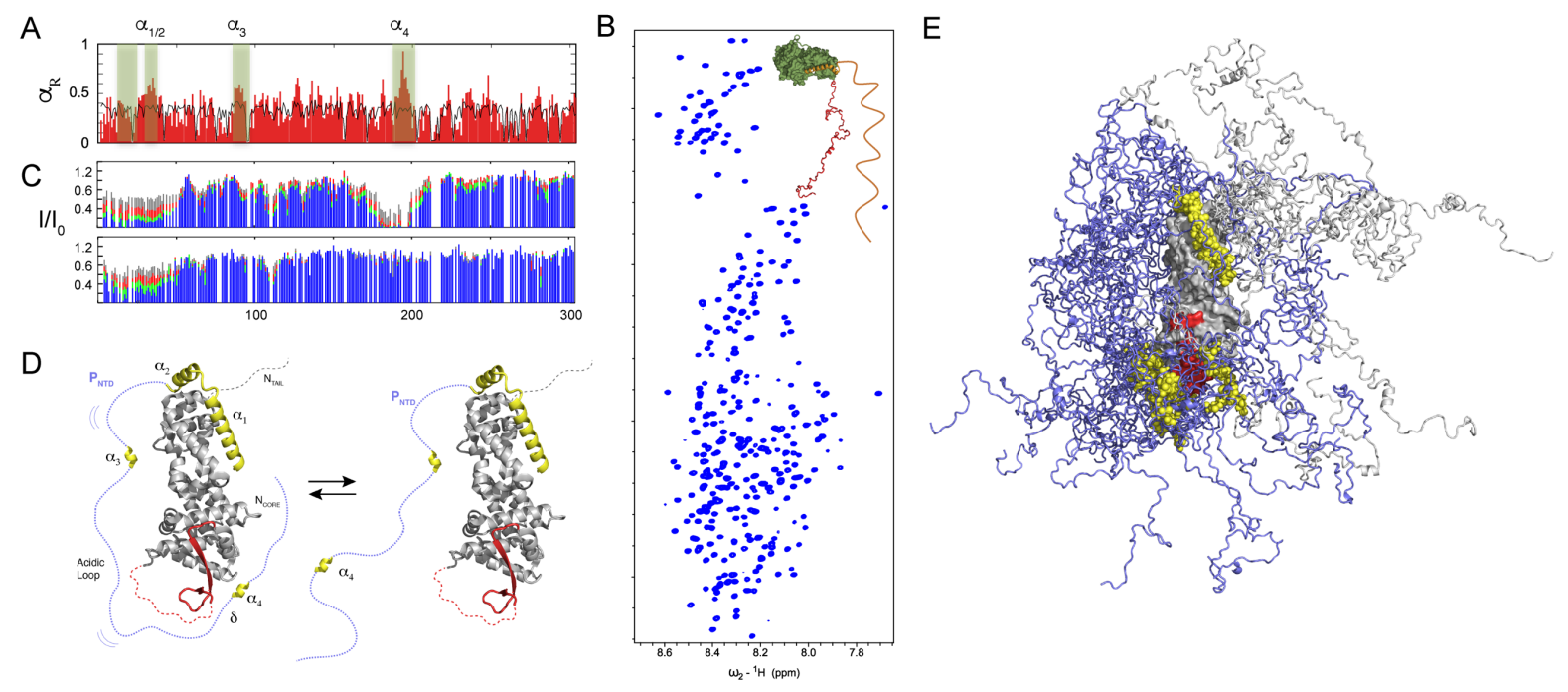


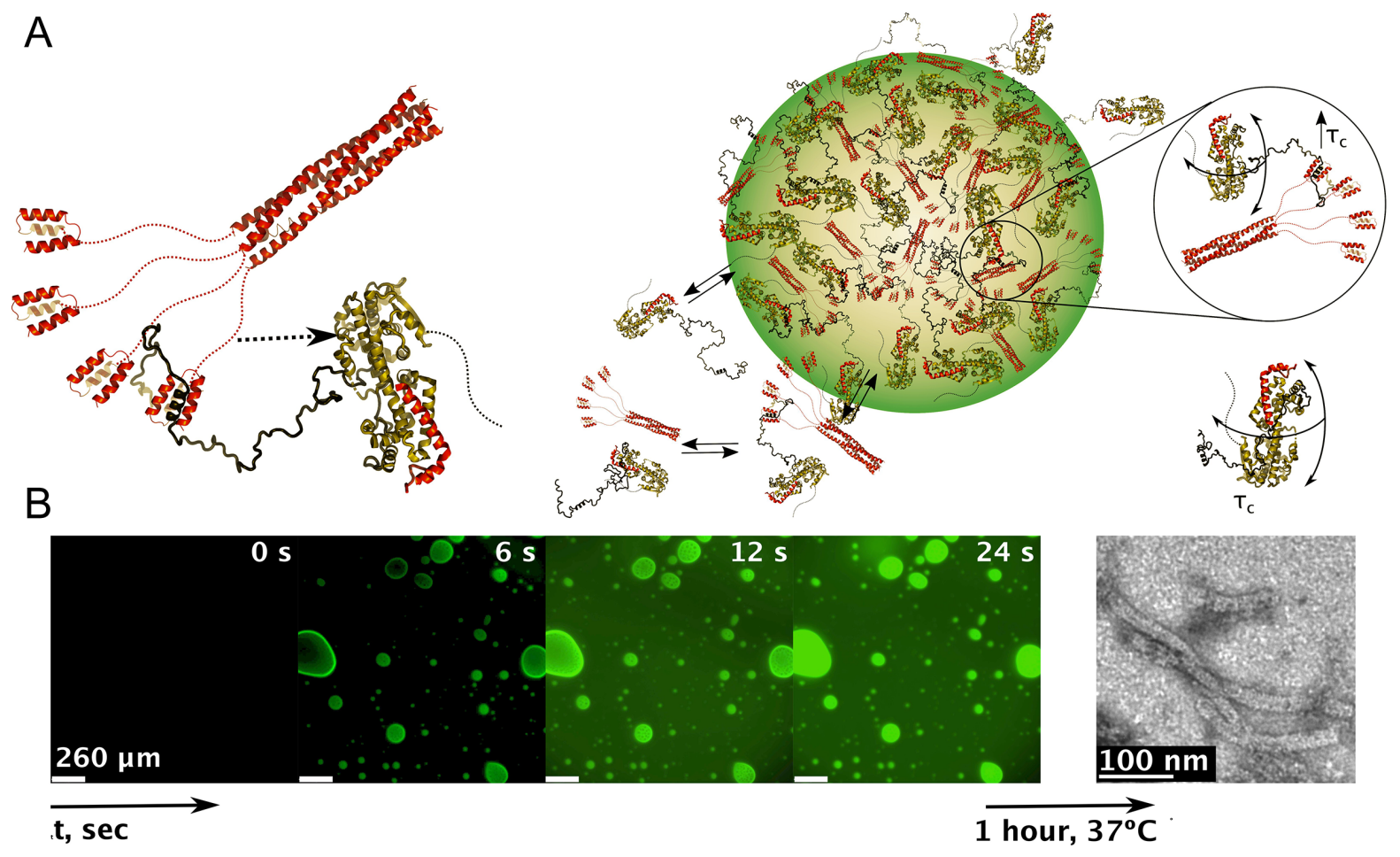




\section{References}

1. Paules $\mathrm{Cl}$, Marston HD, Fauci AS: Measles in $\mathbf{2 0 1 9}$ - Going Backward. New England Journal of Medicine 2019, 380:2185-2187.

2. Tarbouriech N, Curran J, Ruigrok RW, Burmeister WP: Tetrameric coiled coil domain of Sendai virus phosphoprotein. Nat Struct Biol 2000, 7:777-781.

3. Communie G, Crépin T, Maurin D, Jensen MR, Blackledge M, Ruigrok RWH: Structure of the tetramerization domain of measles virus phosphoprotein. J Virol 2013, 87:71667169 .

4. Bruhn JF, Barnett KC, Bibby J, Thomas JMH, Keegan RM, Rigden DJ, Bornholdt ZA, Saphire EO: Crystal structure of the nipah virus phosphoprotein tetramerization domain. J Virol 2014, 88:758-762.

5. Curran J, Kolakofsky D: Replication of paramyxoviruses. Adv Virus Res 1999, 54:403422.

6. Cox R, Plemper RK: The paramyxovirus polymerase complex as a target for nextgeneration anti-paramyxovirus therapeutics. Front Microbiol 2015, 6:459.

7. Longhi S, Receveur-Bréchot V, Karlin D, Johansson K, Darbon H, Bhella D, Yeo R, Finet S, Canard $\mathrm{B}$ : The $\mathrm{C}$-terminal domain of the measles virus nucleoprotein is intrinsically disordered and folds upon binding to the C-terminal moiety of the phosphoprotein. $J$ Biol Chem 2003, 278:18638-18648.

8. Jensen MR, Communie G, Ribeiro EA Jr, Martinez N, Desfosses A, Salmon L, Mollica L, Gabel $\mathrm{F}$, Jamin $\mathrm{M}$, Longhi $\mathrm{S}$, et al.: Intrinsic disorder in measles virus nucleocapsids. Proc Natl Acad Sci USA 2011, 108:9839-9844.

9. Schoehn G, Mavrakis M, Albertini A, Wade R, Hoenger A, Ruigrok RWH: The $\mathbf{1 2} \mathbf{A}$ structure of trypsin-treated measles virus N-RNA. J Mol Biol 2004, 339:301-312.

10. Desfosses A, Goret G, Farias Estrozi L, Ruigrok RWH, Gutsche I: Nucleoprotein-RNA orientation in the measles virus nucleocapsid by three-dimensional electron microscopy. J Virol 2011, 85:1391-1395.

11. Bloyet L-M, Schramm A, Lazert C, Raynal B, Hologne M, Walker O, Longhi S, Gerlier D: Regulation of measles virus gene expression by $\mathrm{P}$ protein coiled-coil properties. Science Advances 2019, 5:eaaw3702.

* Structural features of the tetramerization domain of $\mathrm{P}$ and its interaction with $\mathrm{L}$ are shown to play a role in regulating measles virus gene expression.

12. Milles S, Jensen MR, Lazert C, Guseva S, Ivashchenko S, Communie G, Maurin D, Gerlier $D$, Ruigrok RWH, Blackledge $\mathrm{M}$ : An ultraweak interaction in the intrinsically disordered replication machinery is essential for measles virus function. Science Advances 2018, 4:eaat7778. 
** Investigation of $\mathrm{P}_{\mathrm{TAlL}}$ by NMR, reveals that a second, ultraweak interaction site of $\mathrm{N}$ exists 150 amino acids distant from the $\mathrm{N}$-terminal chaperone site. This interaction is essential for viral replication, rationalizing for the first time the existence of this long disordered domain.

13. Kingston RL, Hamel DJ, Gay LS, Dahlquist FW, Matthews BW: Structural basis for the attachment of a paramyxoviral polymerase to its template. Proc Natl Acad Sci USA 2004, 101:8301-8306.

14. Gely S, Lowry DF, Bernard C, Jensen MR, Blackledge M, Costanzo S, Bourhis J-M, Darbon H, Daughdrill G, Longhi S: Solution structure of the C-terminal $X$ domain of the measles virus phosphoprotein and interaction with the intrinsically disordered Cterminal domain of the nucleoprotein. J Mol Recognit 2010, 23:435-447.

15. Guryanov SG, Liljeroos L, Kasaragod P, Kajander T, Butcher SJ: Crystal Structure of the Measles Virus Nucleoprotein Core in complex with an $\mathbf{N}$-terminal Region of Phosphoprotein. J Virol 2015, doi:10.1128/JVI.02865-15.

16. Nikolic J, Le Bars R, Lama Z, Scrima N, Lagaudrière-Gesbert C, Gaudin Y, Blondel D: Negri bodies are viral factories with properties of liquid organelles. Nat Commun 2017, 8:58.

** Negri bodies are characteristic inclusions found in cells infected by rabies virus. This study demonstrates for the first time that these bodies are formed via liquid-liquid phase separation involving $\mathrm{N}$ and $\mathrm{P}$ proteins.

17. Rincheval V, Lelek M, Gault E, Bouillier C, Sitterlin D, Blouquit-Laye S, Galloux M, Zimmer C, Eleouet J-F, Rameix-Welti M-A: Functional organization of cytoplasmic inclusion bodies in cells infected by respiratory syncytial virus. Nat Commun 2017, 8:563.

18. Zhou Y, Su JM, Samuel CE, Ma D: Measles Virus Forms Inclusion Bodies with Properties of Liquid Organelles. J Virol 2019, doi:10.1128/JVI.00948-19.

** Reveals the liquid-like nature of puncta that colocalize components of measles virus replication machinery observed in cellulo and identifies important domains in the proteins involved.

19. Jensen MR, Zweckstetter $M$, Huang J, Blackledge $M$ : Exploring free-energy landscapes of intrinsically disordered proteins at atomic resolution using NMR spectroscopy. Chem Rev 2014, 114:6632-6660.

20. Bhella $D$, Ralph A, Yeo RP: Conformational flexibility in recombinant measles virus nucleocapsids visualised by cryo-negative stain electron microscopy and real-space helical reconstruction. J Mol Biol 2004, 340:319-331.

21. Gutsche I, Desfosses A, Effantin G, Ling WL, Haupt M, Ruigrok RWH, Sachse C, Schoehn G: Structural virology. Near-atomic cryo-EM structure of the helical measles virus nucleocapsid. Science 2015, 348:704-707. 
22. Milles S, Jensen MR, Communie G, Maurin D, Schoehn G, Ruigrok RWH, Blackledge M: Self-Assembly of Measles Virus Nucleocapsid-like Particles: Kinetics and RNA Sequence Dependence. Angew Chem Int Ed Engl 2016, 55:9356-9360.

23. Albertini AAV, Wernimont AK, Muziol T, Ravelli RBG, Clapier CR, Schoehn G, Weissenhorn W, Ruigrok RWH: Crystal structure of the rabies virus nucleoproteinRNA complex. Science 2006, 313:360-363.

24. Green TJ, Zhang X, Wertz GW, Luo M: Structure of the Vesicular Stomatitis Virus Nucleoprotein-RNA Complex. Science 2006, 313:357-360.

25. Tawar RG, Duquerroy S, Vonrhein C, Varela PF, Damier-Piolle L, Castagné N, MacLellan $\mathrm{K}$, Bedouelle $\mathrm{H}$, Bricogne $\mathrm{G}$, Bhella $\mathrm{D}$, et al.: Crystal structure of a nucleocapsid-like nucleoprotein-RNA complex of respiratory syncytial virus. Science 2009, 326:12791283.

26. Alayyoubi M, Leser GP, Kors CA, Lamb RA: Structure of the paramyxovirus parainfluenza virus 5 nucleoprotein-RNA complex. Proc Natl Acad Sci USA 2015, 112:E1792-1799.

27. Desfosses A, Milles S, Jensen MR, Guseva S, Colletier J-P, Maurin D, Schoehn G, Gutsche I, Ruigrok RWH, Blackledge M: Assembly and cryo-EM structures of RNAspecific measles virus nucleocapsids provide mechanistic insight into paramyxoviral replication. PNAS 2019, 116:4256-4264.

* The structure of the nucleocapsid assembled on known RNA sequences is determined, producing high resolution structural information revealing the register of RNA binding to $\mathrm{N}$ with consequences for the accessibility of the 3 ' genome termination and details of N-RNA interactions in the binding cleft.

28. Guseva S, Milles S, Blackledge M, Ruigrok RWH: The Nucleoprotein and Phosphoprotein of Measles Virus. Front Microbiol 2019, 10:1832.

29. Nodet G, Salmon L, Ozenne V, Meier S, Jensen MR, Blackledge M: Quantitative description of backbone conformational sampling of unfolded proteins at amino acid resolution from NMR residual dipolar couplings. J Am Chem Soc 2009, 131:1790817918.

30. Abyzov A, Salvi N, Schneider R, Maurin D, Ruigrok RWH, Jensen MR, Blackledge M: Identification of Dynamic Modes in an Intrinsically Disordered Protein Using Temperature-Dependent NMR Relaxation. J Am Chem Soc 2016, 138:6240-6251.

31. Yabukarski F, Lawrence $P$, Tarbouriech N, Bourhis J-M, Delaforge E, Jensen MR, Ruigrok RWH, Blackledge M, Volchkov V, Jamin M: Structure of Nipah virus unassembled nucleoprotein in complex with its viral chaperone. Nat Struct Mol Biol 2014, 21:754759. 
32. Hanke L, Schmidt FI, Knockenhauer KE, Morin B, Whelan SP, Schwartz TU, Ploegh HL: Vesicular stomatitis virus $\mathbf{N}$ protein-specific single-domain antibody fragments inhibit replication. EMBO Rep 2017, 18:1027-1037.

33. Ouizougun-Oubari M, Pereira N, Tarus B, Galloux M, Lassoued S, Fix J, Tortorici MA, Hoos S, Baron B, England P, et al.: A Druggable Pocket at the Nucleocapsid/Phosphoprotein Interaction Site of Human Respiratory Syncytial Virus. J Virol 2015, 89:11129-11143.

34. Sourimant J, Thakkar VD, Cox RM, Plemper RK: Viral evolution identifies a regulatory interface between paramyxovirus polymerase complex and nucleocapsid that controls replication dynamics. Science Advances 2020, 6:eaaz1590.

* Reveals intriguing multipartite interactions between P-XD and $\mathrm{N}_{\text {TAIL }}$ which interact with $L$ and a region on the surface of $N_{\text {CORE }}$ that controls replication dynamics.

35. Communie G, Ruigrok RW, Jensen MR, Blackledge M: Intrinsically disordered proteins implicated in paramyxoviral replication machinery. Current Opinion in Virology 2014, 5:72-81.

36. Delpeut S, Noyce RS, Siu RW, Richardson CD: Host factors and measles virus replication. Curr Opin Virol 2012, 2:767-777.

37. Thomas SM, Lamb RA, Paterson RG: Two mRNAs that differ by two nontemplated nucleotides encode the amino coterminal proteins $\mathbf{P}$ and $\mathbf{V}$ of the paramyxovirus SV5. Cell 1988, 54:891-902.

38. Cattaneo R, Kaelin K, Baczko K, Billeter MA: Measles virus editing provides an additional cysteine-rich protein. Cell 1989, 56:759-764.

39. Curran J, Boeck R, Kolakofsky D: The Sendai virus P gene expresses both an essential protein and an inhibitor of RNA synthesis by shuffling modules via mRNA editing. EMBO J 1991, 10:3079-3085.

40. Precious B, Young DF, Bermingham A, Fearns R, Ryan M, Randall RE: Inducible expression of the $P, V$, and NP genes of the paramyxovirus simian virus 5 in cell lines and an examination of NP-P and NP-V interactions. J Virol 1995, 69:8001-8010.

41. Milles S, Mercadante D, Aramburu IV, Jensen MR, Banterle N, Koehler C, Tyagi S, Clarke J, Shammas SL, Blackledge M, et al.: Plasticity of an Ultrafast Interaction between Nucleoporins and Nuclear Transport Receptors. Cell 2015, 163:734-745.

42. Novoa RR, Calderita G, Arranz R, Fontana J, Granzow H, Risco C: Virus factories: associations of cell organelles for viral replication and morphogenesis. Biology of the Cell 2005, 97:147-172.

43. Netherton C, Moffat K, Brooks E, Wileman T: A Guide to Viral Inclusions, Membrane Rearrangements, Factories, and Viroplasm Produced During Virus Replication. In Advances in Virus Research. . Academic Press; 2007:101-182. 
44. Banani SF, Lee HO, Hyman AA, Rosen MK: Biomolecular condensates: organizers of cellular biochemistry. Nat Rev Mol Cell Biol 2017, 18:285-298.

45. Nott TJ, Craggs TD, Baldwin AJ: Membraneless organelles can melt nucleic acid duplexes and act as biomolecular filters. Nature Chemistry 2016, 8:569-575.

46. Wei M-T, Elbaum-Garfinkle $\mathrm{S}$, Holehouse AS, Chen CC-H, Feric M, Arnold CB, Priestley RD, Pappu RV, Brangwynne CP: Phase behaviour of disordered proteins underlying low density and high permeability of liquid organelles. Nat Chem 2017, 9:1118-1125.

47. Shin $\mathrm{Y}$, Brangwynne $\mathrm{CP}$ : Liquid phase condensation in cell physiology and disease. Science 2017, 357:eaaf4382.

48. Lahaye X, Vidy A, Pomier C, Obiang L, Harper F, Gaudin Y, Blondel D: Functional Characterization of Negri Bodies (NBs) in Rabies Virus-Infected Cells: Evidence that NBs Are Sites of Viral Transcription and Replication. Journal of Virology 2009, 83:7948-7958.

49. Heinrich BS, Maliga Z, Stein DA, Hyman AA, Whelan SPJ: Phase Transitions Drive the Formation of Vesicular Stomatitis Virus Replication Compartments. MBio 2018, 9.

50. Zhang S, Chen L, Zhang G, Yan Q, Yang X, Ding B, Tang Q, Sun S, Hu Z, Chen M: An Amino Acid of Human Parainfluenza Virus Type 3 Nucleoprotein Is Critical for Template Function and Cytoplasmic Inclusion Body Formation. Journal of Virology 2013, 87:12457-12470.

51. Li Z, Guo D, Qin Y, Chen M: PI4KB on Inclusion Bodies Formed by ER Membrane Remodeling Facilitates Replication of Human Parainfluenza Virus Type 3. Cell Reports 2019, 29:2229-2242.e4.

52. Omi-Furutani M, Yoneda M, Fujita K, Ikeda F, Kai C: Novel phosphoprotein-interacting region in Nipah virus nucleocapsid protein and its involvement in viral replication. $J$ Virol 2010, 84:9793-9799.

53. Derdowski A, Peters TR, Glover N, Qian R, Utley TJ, Burnett A, Williams JV, Spearman P, Crowe JE: Human metapneumovirus nucleoprotein and phosphoprotein interact and provide the minimal requirements for inclusion body formation. $J$ Gen Virol 2008, 89:2698-2708.

54. Spehner D, Drillien R, Howley PM: The Assembly of the Measles Virus Nucleoprotein into Nucleocapsid-like Particles Is Modulated by the Phosphoprotein. Virology 1997, 232:260-268.

55. Nakatsu Y, Takeda M, Ohno S, Shirogane Y, Iwasaki M, Yanagi Y: Measles Virus Circumvents the Host Interferon Response by Different Actions of the $\mathbf{C}$ and $\mathbf{V}$ Proteins. Journal of Virology 2008, 82:8296-8306.

56. Ma D, George CX, Nomburg JL, Pfaller CK, Cattaneo R, Samuel CE: Upon Infection, Cellular WD Repeat-Containing Protein 5 (WDR5) Localizes to Cytoplasmic Inclusion 
Bodies and Enhances Measles Virus Replication. Journal of Virology 2018, 92:e0172617.

57. Hoenen T, Shabman RS, Groseth A, Herwig A, Weber M, Schudt G, Dolnik O, Basler CF, Becker S, Feldmann $\mathrm{H}$ : Inclusion bodies are a site of ebolavirus replication. J Virol 2012, 86:11779-11788.

58. Pont VD, Jiang Y, Plemper RK: Bipartite interface of the measles virus phosphoprotein $X$ domain with the large polymerase protein regulates viral polymerase dynamics. PLOS Pathogens 2019, 15:e1007995.

59. Longhi S, Bloyet L-M, Gianni S, Gerlier D: How order and disorder within paramyxoviral nucleoproteins and phosphoproteins orchestrate the molecular interplay of transcription and replication. Cell Mol Life Sci 2017, 74:3091-3118.

60. Brunel J, Chopy D, Dosnon M, Bloyet L-M, Devaux P, Urzua E, Cattaneo R, Longhi S, Gerlier D: Sequence of Events in Measles Virus Replication: Role of PhosphoproteinNucleocapsid Interactions. J Virol 2014, 88:10851-10863.

61. Bloyet L-M, Brunel J, Dosnon M, Hamon V, Erales J, Gruet A, Lazert C, Bignon C, Roche $P$, Longhi $S$, et al.: Modulation of Re-initiation of Measles Virus Transcription at Intergenic Regions by PXD to NTAIL Binding Strength. PLoS Pathog 2016, 12:e1006058.

62. Posey AE, Holehouse AS, Pappu RV: Phase Separation of Intrinsically Disordered Proteins. Meth Enzymol 2018, 611:1-30.

63. Guseva S, Milles S, Jensen MR, Salvi N, Kleman J-P, Maurin D, Ruigrok RWH, Blackledge $M$ : Measles virus nucleo- and phosphoproteins form liquid-like phase-separated compartments that promote nucleocapsid assembly. Science Advances 2020, 6:eaaz7095.

** The phenomenon of phase separation upon mixing of $\mathrm{N}$ and $\mathrm{P}$ is examined in detail in vitro, revealing the essential sites and their mechanisms of stabilization of the viral droplets and allowing observation of assembly of nucleocapsid like particles upon recruitment of RNA.

64. Cattaneo R, Rebmann G, Schmid A, Baczko K, ter Meulen V, Billeter MA: Altered transcription of a defective measles virus genome derived from a diseased human brain. EMBO J 1987, 6:681-688.

65. Jenni S, Bloyet L-M, Diaz-Avalos R, Liang B, Whelan SPJ, Grigorieff N, Harrison SC: Structure of the Vesicular Stomatitis Virus L Protein in Complex with Its Phosphoprotein Cofactor. Cell Reports 2020, 30:53-60.e5.

66. Horwitz JA, Jenni S, Harrison SC, Whelan SPJ: Structure of a rabies virus polymerase complex from electron cryo-microscopy. PNAS 2020, 117:2099-2107. 
67. Cao D, Gao Y, Roesler C, Rice S, D'Cunha P, Zhuang L, Slack J, Domke M, Antonova A, Romanelli $S$, et al.: Cryo-EM structure of the respiratory syncytial virus RNA polymerase. Nat Commun 2020, 11:368.

68. Pan J, Qian X, Lattmann S, El Sahili A, Yeo TH, Jia H, Cressey T, Ludeke B, Noton S, Kalocsay $\mathrm{M}$, et al.: Structure of the human metapneumovirus polymerase phosphoprotein complex. Nature 2020, 577:275-279.

69. Abdella R, Aggarwal M, Okura T, Lamb RA, He Y: Structure of a paramyxovirus polymerase complex reveals a unique methyltransferase-CTD conformation. Proc Natl Acad Sci USA 2020, 117:4931-4941. 